\title{
Classing Early Intervention: Social Class, Occupational Moralities and Criminalization
}

\begin{abstract}
Daniel J McCarthy
This article interrogates the nature of judgements used by social control professionals to identify signs of anti-social behaviour amongst young people and families referred to early intervention programs. The emphasis of professionals working within such networks is mostly benevolent in seeking to support and direct specific services at particular individuals. This article traces the effects of these processes of social control in action, specifically the ways through which professionals' judgements formed around the normative social class status of clients become prime reasons for intervening. The article reflects on the ways occupational moralities translate social class judgements into control responses, arguing that one of the principal outcomes of early intervention is class correction rather than crime control.
\end{abstract}

\section{Key words}

Early Intervention, Social Class, Social Control, Occupational Moralities, Anti-Social Behaviour

\section{Manuscript}

The framing of anti-social behaviour through media and political discourses is synonymous with representations of social class deficit. From judgements about the status of families living on council estates, the conduct of 'irresponsible' parents, to the 'antisocial' actions of lower-class young people, there is a certain repetitive cycle of anxieties about forms of class culture which are deemed 'bad', 'wrong', or in need of 'correction'. Since it first came to the forefront of New Labour policy during the late 1990s, the politics of anti-social behaviour (ASB) has been linked by many commentators to the criminalisation of the working classes (Goldson, 2000, Burney, 2005, Gillies, 2005, Squires and Stephen, 2005, Garrett, 2006). The Respect Agenda which received high levels of media coverage during the 2005 general election, brought to the forefront of its campaign issues regarding 'proper' civility, morality, and in particular problems associated with the disorderly culture of the non-respectable white working-classes (Labour Party, 2009). Highly symbolic publicity campaigns delivered by the New Labour government (e.g. Home Office, 2003, Respect Task Force, 2006) have been used in conjunction with a substantial increase in the types of legislative tools available to local agencies to combat problems of ASB (Rutherford, 2000, Squires, 2006). These legislative tools have included sanctions such as ASBOs, parenting orders, and a host of powers given to housing landlords to deal with 'disorderly' tenants, most of which have been targeted at socially marginal populations, such as those living in social 
or council housing, homeless populations, single parent mothers, and working-class young people (Goldson and Jamieson, 2002, Nixon and Hunter, 2009).

Largely in response to criticisms of the Respect Agenda's (Respect Task Force, 2006) overwhelming focus on enforcement, there was a clear shift in emphasis by the state towards a focus on a range of preventative responses known collectively as 'early intervention'1. The introduction of Gordon Brown as Prime Minister in 2008 brought with it changes to the direction of the Labour Governments youth crime strategy, notably the publication of two important documents - the Youth Crime Action Plan (Home Office, 2008) and the Youth Taskforce Action Plan (2008). These strategies focused on the merits of directing support towards 'at risk' youth in order to divert them away from criminality and other social problems. In many local areas these have seen the closer involvement of agencies working in collaboration with one another, ranging from information sharing networks, to operating early intervention initiatives and similar diversionary programs. These include neighbourhood policing teams who engage in informal diversionary activities with young people, parenting support programs such as Sure Start, community wardens used to identify families 'at risk' of crime, as well as outreach youth workers providing youth diversionary provision in many disadvantaged communities.

There has been some scepticism regarding the affects of agency intervention in preventive initiatives involving 'at risk' young people and families. One theme has consisted of the tendency to socialise program participants through idealised middle class norms, including the correction of 'bad' attitudes and values quite separate to the reasons for the initial support-based goals of the intervention (Clarke, 2006, Hey and Bradford, 2006). These themes have been articulated through concepts such as 'net widening' and 'mesh thinning' (Cohen, 1979, 1985) to emphasise how diversionary and related preventive initiatives can target and sweep different groups into a range of social control nets under the guises of 'support' and 'assistance'. In the context of diversionary programs, high levels of discretion are accorded to social control professionals, allowing the formulation of judgements regarding the potentials as well as the actual realities of the individuals offending behaviour. In relation to the themes of this article, judgements are commonly directed at the moral respectability of clients, including cultural distinctions based around character defects, poor attitudes, and lack of willingness to change behaviour, which often influence the nature and trajectory of decision-making outcomes. The work of authors such as Bev Skeggs (1997, 2004), Finch (1993) and a number of others (Savage, 2000, Lawler, 2005, Johnson, 2008) have attempted to recompose understandings of social class as frameworks for analysing how relational ideas of taste, consumption, status, and aesthetic judgements of lack, filter and reproduce class differences. To date there has been scarce empirical examination of the ways social class judgements are employed by social control professionals involved in the everyday implementation of early intervention programs. Specifically this includes how benevolent intentions which aim to assist young people and families 'at risk' of crime, create pathways of social control through emphasis on class status, rather than simply involvement in crime or ASB. This article draws on a two-year ethnographic study into the operations of early intervention programs focusing on the collaborative roles of police officers, social workers, housing officers and other social control professionals. 


\section{Anti-Social Behaviour and the Ubiquitous Effects of Class}

The policy context of this article concerns legislative responses to ASB under the framework of the Crime and Disorder Act (CDA) (1998), thereafter supported by numerous policy revisions (Home Office, 2003, Respect Task Force, 2006). The initial purpose of the legislation was relatively mixed. On the one hand the act included fairly progressive attempts to improve multi-agency partnership working between statutory and voluntary agencies, including the establishment of youth offending teams who replaced the police's previous domination of cautioning and charging procedures against young people (Goldson, 2000, Souhami, 2007). However, the CDA was most notable for its controversial introduction of tools such as anti-social behaviour orders (ASBOs), curfews, and parenting orders (see Burney, 2005, Squires and Stephen, 2005 for analysis of these policy developments). The role of the Together campaign - introduced in 2002 to persuade and align local professionals to make greater use of ASB powers, was to substantially increase the use of ASBOs, curfews, parenting orders, and newly created housing tenancy injunctions. The Together campaign received substantial criticism for its 'get tough' rationale which largely reduced the Labour Party mantra of 'tough on crime, tough on the causes of crime' to focus on the former at the expense of the latter (Jamieson, 2005). As a consequence of criticisms accusing the New Labour government of prioritising enforcement over prevention, there was an important change of tack culminating in much closer emphasis on 'early intervention' and social crime prevention (Youth Taskforce Action Plan, 2008).

The shift towards early intervention by the New Labour government was heavily influenced by research carried out by a team of psychiatrists commissioned by the Home Office (Scott et al, 2001, Scott, 2002) whose work suggested that behavioural conditions and ASB in early years, if tackled early, could lead to greater preventive benefits in later life. Whilst the 'ground level' realities of agencies implementing these precise scientific rationales has been patchy, there have been several key changes brought about by the state's focus on 'early intervention'. Agencies, including the police, the youth justice service, and children's services have become increasingly 'risk targeted' - encouraged to increasingly 'act early' especially in the wake of enquiries stressing the need for widespread information sharing (Parton, 2006). Away from social welfare services, this has also involved changes to the role of the police, particularly under the rubric of Neighbourhood Policing which has encouraged police officers to 'befriend' and work closely to divert young people away from criminality, as well as to work more closely with social welfare agencies (Home Office, 2004, 2010, ACPO, 2008).

There has been a certain ambivalence regarding the uses of so-called diversionary interventions targeted at groups deemed 'at risk' of offending. Amongst many scholars, particularly those influenced by developmental psychology, there is a shared sense of optimism that acting early can create positive outcomes for young people (Loeber, 1982, Rutter et al, 1998, Farrington and Welsh, 2006, Farrington 2007). There is ample evidence to indicate that ASB is most commonly found in economically deprived areas (Millie et al, 2005), with patterns of victimisation and offending also interlinked with this picture (Hayward and Sharp, 2005). The vast catalogue of research from the U.K and North America has drawn attention to the linkages between early years ASB and 
offending into adulthood (see Rutter et al, 1998 for reviews), much of which has found close linkages between socio-economic disadvantage, psychological disorders and offending activities.

Amongst dissenting scholars, notably those aligned with critical labelling traditions there has been scepticism over the linkages between the precise risk factors which lead to crime, particularly the role of diversion as modes of intervention (Blomberg 1977, Cohen, 1979, 1985). The basis of these critiques have not been so much cynical of the spirit, or indeed the notion that alternatives to the criminal justice system are indeed legitimate and necessary, but rather the ways through which programs entrap and sweep-in children and young persons who are often not formally engaged in criminality. McAra and McVie (2005) in their study of two control groups of workingclass males living in high levels of deprivation confirmed that that those caught and processed into a range of 'diversionary' interventions continued offending for longer periods compared to those receiving no intervention. Furthermore, those receiving more intense forms of intervention were primarily non-respectable class subjects whose behaviour accorded less discretion and more consistent rule-following responses from the police.

This article will develop an alternative framing of social class as a key explanatory feature for many of the responses and rationales of the social control actors involved in implementing early intervention programs. Class in my analysis will be analysed as a concept which posits relational distinctions, rather than through conventional categorical markers such as income and occupational status. This will draw from the original ideas of Bourdieu (1986), which has been mostly associated with understandings of social class and social inequalities, with more recent extensions of his work into gender. 'Race' and ethnicity have been less readily applied through his analytic frameworks. Whilst this is not an article necessarily about 'race' and ethnicity, a few potential applications are offered. Bourdieu (1991) in attempting to move away from a binary differentiation model of symbolic classifications recognises some room for dynamism. Wimmer (2008) has drawn from Bourdieu and aligned thinkers in building a model of ethnic boundaries which analyses fields of power and the constellation of symbolic classifications which are negotiated through these, suggesting a more dynamic understanding of race and ethnicity which does not fall into static categories. 'Race' and ethnicity as symbolic classifications carrying the weight of their historical and cultural loads should not be divorced from 'classing' distinctions (e.g. tastes, dress, accent etc). For example, Hartigan Jnr (1999) detailing the uneven and dynamic processes by which identities of 'whiteness' and 'blackness' are constructed in differential ways within ethnic groupings, recognises that notions of 'race' and ethnicity are indeed heavily conditioned by class-based schema.

It will be argued during this article that the classifications employed by professionals towards the constitution of signs of antisocial or risky behaviour are often themselves embodiments of class, based upon notions of 'deficit' and 'lack' which draw upon a set of cultural representations of lower class culture as a group in need of control and order (see Bourdieu, 1986, Skeggs, 1997, Lawler, 2005). This will detail how social control professionals construct, judge, and respond to certain signs and behaviours, employing these judgements towards the condemnation of certain clients as part of the 'making up' of class distinctions (Bourdieu, 1986, Skeggs, 1997). 


\section{Data Sources and Field Settings}

The empirical material informing this article is based on a two-year ethnography of precourt case conferences in two outer London (UK) areas used to divert and process cases involving primarily children and young people. The original decision to select two areas (Shore Acres and Hobart - both pseudonyms) was to increase the generalisability of the findings by selecting two contrasting areas in assessing how institutional responses differed between each locale. Both areas were of similar demographic profiles primarily White, British, with large divergences in distinct neighbourhoods, but differed in terms of service provision and infrastructure with Hobart having a well established number of policing and social work teams operating outreach provision.

During the course of the fieldwork, I was engaged in overt observation of a range of settings. This consisted mainly of passively listening and recording information in forums such as case conferences, for which I was granted permission to write fieldnotes by the agencies attending the meetings, under the main condition that places and client details were made anonymous. The fieldwork also consisted of formal interviews with 18 professionals ${ }^{2}$ lasting from 45 mins to 2 hours. This also included regular informal interviews during the course of the fieldwork. Whereas informal interviews involved brief discussions usually before and after meetings, the formal interviews were carried out at the end of the research in a setting external to the case conferences (usually the professionals' office).These were used to clarify and validate any observations gathered during the overall fieldwork. To ensure that this information was gathered accurately, the interviews were tape recorded and transcribed in full. Unless information was given to me with the disclaimer of terms like 'off the record' or 'don't go repeating this', information was used as data. It should be mentioned that in both locations, the author was involved in carrying out other research projects for the police and other agencies which were initially separate to the fieldwork informing this article. This certainly contributed to the acceptance of my research, as well as substantially increasing trust relations, and supporting access to a range of materials which would perhaps have been otherwise obstructed.

The case conferences included round table discussions regarding referred individuals who had shown sufficient warning signs which highlighted potential involvement in future criminality or forms of risk/vulnerability. Professionals from agencies such as the police, housing landlords, mental health services, social services, youth agencies, and substance misuse teams would meet regularly to exchange information about the referred individuals and attempt to devise interventions which attempted to forestall or divert them from the criminal justice system. The referrals could be made from any agency, but tended to come from enforcement-based agencies such as the police and housing associations. It was found that more 'welfare' orientated agencies, including voluntary drop-in centres, the youth justice service and children's services would make far less referrals due to the feeling that their own agencies were doing sufficient work with clients without requirement for a multi-agency response ${ }^{3}$. Although client participation in 'early intervention' initiatives were voluntary, refusing help or assistance can often be treated as a sign of non-engagement and can carry more negative 
ramifications further down the line, particularly if more formalised sanctions such as ASBOs and Parenting Orders are employed.

From a combination of attendance at case conference panels and from access to supporting case referral documents, a total of 204 qualitative case studies were collected during the fieldwork period, with each case followed over a course of months in order to track the processes and trajectories of interventions. Although no formal legal powers were invested in the case conference panels, decisions could be used to secure enforcement action in the form of juridical or welfare-based sanctions through the mandate of an individual agency. As forthcoming data shows, although the case conferences were multi-agency based, the police often structured and dominated proceedings (Foster, 2002, Skinns, 2008).

\section{Discovering Disorder}

The overarching principle of early intervention programs is to identify young people and families who are perceived to be 'at risk' of offending activities, and direct services to forestall or limit these behaviours. What prevail are structures of identification commonly involving what some may consider banal symptoms of potential offending. These include untidy homes, shouting and screaming in the home, classroom horseplay, children wearing dirty clothes, to name just a few examples. Whilst these observations and their equation with criminality are obviously far from certain, the focus on these banal or spurious aspects of behaviour instead become forms of intervention in their own right, quite separate to the original intentions in preventing crime amongst young people. Through these practices of identifying potentially problematic persons, professionals actively construct signs of class and non-respectability as requiring forms of correction and sometimes criminalisation.

The predominant types of individual referred to the case conferences are typically males aged 12 to 15 , often living in higher crime and socially disadvantaged neighbourhoods. These demographic profiles were largely due to disproportionate profiling and surveillance by many agencies in social housing estates in both areas. Females, who although fewer in overall numbers of referrals, received somewhat different judgments relating to their perceived level of risk and behaviour based specifically around their 'vulnerable' status. These gendered judgments also extended into the referrals for families, many of which were female-headed, which invariably concentrated upon perceived deficits of parenting (Nixon and Hunter, 2009):

The case involves $\mathrm{X}$ family - a young family who are the family from hell... Single mum, kids running riot, no responsibility for their behaviour, late night parties, trashing the communal areas. The other residents in the block are elderly and quite intimidated. They are reluctant to go to court to give evidence. [Extract from Case Conference, Beth, Housing Officer - Shore Acres]

I have wider concerns about the state of the house being a symptom and not a cause of the situation. They say 'oh you don't live with adolescents you don't know', but I do live with adolescents and my house does not look like that. Their 
mindset needs to be changed and challenged. The issues have become everyone else's problems. [Extract from Case Conference, Becky, Police Sgt- Hobart]

The decisions to represent the cases through the style and language used are vital in establishing a broader 'classing gaze' (Finch, 1993) of the mothers conduct. Phrases like 'I live with adolescents and my house doesn't look like that' are used as markers to frame lack of responsibility and purposeful neglect of their parental duties, as well as conveying a wider negative representation of single parent mums. The words 'family from hell' used in the first quote are also reflective of similar connotations. The popular cultural meaning of this term has readily been used within the mass media and political rhetoric through reality television shows like Neighbours from Hell which portray a shared image of the 'bad' and 'excessive' habits of the working class, and often female headed family. The use of these narratives also coincided with the New Labour government's stigmatization of single parent mothers, framing the family as the site of ASB and its capacities to nurture future criminal offspring (Gillies, 2008, also examples in Home Office, 2003, Respect Taskforce, 2006). Although the issues in the above quotes may have some reality, the terms used demarcate conduct by 'looking down' on these 'others' (Skeggs, 2004) - a claim of moral superiority by the professionals (Becky especially in the previous case) through the use of their own experiences of parenting as a marker for establishing non-respectability.

The role of professionals directing the use of services, despite the alleged voluntary participation of clients, reflected considerable differences in the uses of power and authority. Early intervention and tutelary practices were closely intertwined with judgements of the moral character of the young person or parent dictated by the extent to which they were seen to be engaging with agencies. Given the clients exclusion from case conference meetings, it was often left to professionals to form judgements about how far the persons concerned were sincere or active in their attempts to change their behaviour and conduct. The following quote illustrates how clients are deemed as complying and working with agencies:

Diana [Police Community Support Officer - $\mathrm{PCSO}^{4}$ ] 'I'm engaging well with Tom [11 year old boy] and he is finally opening up', which she presented as a positive development.

Katrina [Police Inspector, chair of meeting]: 'Is there is any intell [intelligence] on him'.

Kate [Police officer]: 'No intell at the moment'.

Trish [Police officer]: 'There was a lot discovered after Christmas when stolen goods were found in his room and concerns about where he was getting it'.

Julie [Police officer]: 'I would like to keep on to see if his behaviour continues to decline'.

Sarah [Social worker]: 'I had a long conversation with Tom. I think I'm doing similar stuff to Diana. I have tried to implement a reward system for Tom, for example at school there is a scheme to do outside work like horticulture and so on, but the school won't let him do that until his behaviour improves. When I first saw him he was a little boy with nothing to lose. His father would also stop him going out meaning he had nothing to work for. He just would give up and be 
naughty. He was a bit depressed when I saw him. The reward system seems to be working though. His attendance and behaviour at school has been good all week'. Katrina: 'Sounds positive to me. It's great that you've explained this to the parents. They seem like they're on board and responding well to the help'. [Extract from Case Conference - Hobart]

Similar cases also illustrated the reverse of this, during which the family unit was judged by professionals to be an undesirable controlling environment, with specific attention directed at the lack of 'willingness' of the mother in failing to adopt the advice given by professionals:

We had one where the mother wouldn't cooperate with us at all. She was very much 'this has got nothing to do with you' - very very dismissive of us. That was one where we did get the $\mathrm{ASBI}^{5}$ quite successfully because she portrayed the same image in court and the judge was like 'you have to take some responsibility for it'. Another case which we've got currently is that the parents are very laid back and don't really see that there is a problem. You know you go and see them, you lay it on the line, and you couldn't be any firmer with them and they are just like 'umm, yeah'. It astounds me because I am standing there with the police, the council and they are not taking any of it seriously. The parents that generally work with us are generally the ones you won't see with an ASBI because they are trying to do everything they can to work with us and other agencies to deal with their children's behaviour. Families like that we will work with and we will make every effort with. It's the ones where they think everything is everyone else's problems 'it's not our problem', you know [laughs]'. [Interview with Beth, Housing Officer - Shore Acres]

Even in cases where it could be shown that the parent/s or young people involved were still carrying out acts of ASB, the degree to which they were judged to be cooperating with agencies - such as attending meetings with professionals, seeking help from other support agencies, or even simply acknowledging their culpability - often reduced the chances of any sanctions being invoked against the persons involved. Due to gaps in some of the information shared during the case conferences, a sample of 40 cases were selected where clear discussions of engagement issues with agencies took place. From these, 26 cases involved a clear reduction or withdrawal in the use of sanctions and juridical enforcement of clients, with 14 cases showing partial or no change in terms of sanctions given in proceeding case judgements. The subtle hand of the carer can at times mix with the iron fist of the dogmatist, what David Rothman refers to in ironical prose that 'programs may be administered in the best interests of officials, not clients' (Rothman, 1978:79).

Although for all intents and purposes, the clients described in this article could arguably be described as lower-working class within popular connotations ${ }^{6}$, their subject position as people who need to be 'corrected' in some way rests on their perceived responsiveness to listen and comply with professionals as a mode of accepting that their behaviour and conduct needs to change in order to become independent again. This theme of working-class 'rescue' is one which has a deep historical context (Platt, 1969, 
Donzelot, 1978, Finch, 1993, Roberts, 1999), formed against the backdrop of a contemporary social climate where connotations of state intervention are reserved for those unable to ensue adequate control of matters such as parenting.

\section{Individualising Social Predicaments}

Street-level bureaucracies are regularly involved in making everyday decisions about the credibility or worthiness of different clients. This commonly rests on initial decisions made about the demeanour, status or background information from past cases involving contact with the family of the young person. In addition, factors such as perceived compliance or adherence to advice given by professionals can also be used to determine the extent to which a client is treated favourably or unfavourably (Emerson, 1969, Maynard Moody and Muscheno, 2003). The need to control clients is in part structured by the work environment consisting of heavy caseloads, limited resources, and managerial pressures such as targets and related performance indicators. These types of organisational pressure are also connected to occupational cultures which impact on service delivery and differential responses to clients. As a host of studies have argued, 'people processing institutions' such as police, social service, and housing departments, commonly determine the moral worth and credibility of clients based upon high levels of discretion to invoke prejudice and forms of bias through the law (Lipsky,1980, Harris, 2008 amongst others). This was frequently played out during rather ambivalent responses to issues of culpability regarding young people engaged in ASB, most often involving questions about parental responsibilities:

Jim, an 11 year old boy was introduced by Gordon, the local Police Community Support Officer on the grounds that he had been breaking into the neighbour's garden to play football, as well as highlighted as causing problems at school. Jim's mum and dad had recently split up resulting in Jim living with his mum in a small house on the Edgeside estate. His mum was accused of 'neglectful parenting' for leaving Jim unattended until $6 \mathrm{pm}$ because of her job at ASDA working as a till assistant. The mum was reported to have turned down welfare benefits in order to keep her job, but nonetheless seemed to be the one being castigated by the professionals. As Liz, the social worker summed up 'this may sound controversial but surely you don't have children and leave them alone... I know how hard it is for a single mum, but she is going to have to take responsibility. It's the case of her helping herself'. [Extract from Case Conference - Shore Acres]

Individualising social predicaments often occurred when the professionals' beliefs about responsible parenthood were challenged when breaches of duty or forms of child neglect by the parent/s took place. In the case of the previous case example, the work ethic of the mother whose attempts to carry out a full time job in order to avoid welfare, as well as trying to bring up an 11 year old son, were firmly displaced. The focus on 'being a good mother' (rarely father) accords with a deep-seated political and economic distinction about independence, thrift and hard work (Dodson, 2007). Although the surround culture of neo-liberal thinking may herald impetus to the idea of 'individualising social 
predicaments' (Baker, 2009), there are other factors which certainly explain this type of response, particularly the effects of occupational cultures of agencies such as the police and social services. Responses to the sorts of cases shown above were often conditioned by moralities of professionals' involved in social welfare issues, connected with fundamental 'values' and 'missions' of their occupational identities. There were sometimes inter-organisational tensions during decisions, often involving the police and social workers. For the most part however there was a shared sense of duty when it came to 'early intervention' cases. This could be seen clearly during responses to cases where circumstances made it difficult to change a young person. Evident were not so much vindictive judgements, but rather beliefs about young people as 'changeable' and 'redeemable'. Although with some subtle differences between social workers and police officers, there were similarities in their overriding values:

I don't think I'd say it's too late. It's not my belief in human nature. One of my core values is that most people can change. I think that some people are so damaged that might take a lot longer. I don't think it's ever too late. This is the whole preventative thing isn't it. From the criminal justice side we get a lot of individuals coming into the system for assaulting people at home. When we check with the families or social services they say 'yes there was a referral earlier'. So in terms of a negative outcome for that young person getting a criminal conviction. The criminal justice agencies shouldn't be the ones sorting this out. [Interview with Jacqui, Youth Offending Support Officer - Hobart]

I think it's never too late to try. It might be something lacking in their life and you know, they see the light and change. Umm, I can think of some cases where it doesn't matter what interventions you put in place, they are never going to change. I don't know where is that point because I can think of different people at different ages who have reached that stage. So I don't know what it is, but yes we do try. [Interview with Isabel, Police Officer - Shore Acres]

As explained earlier during this article, professionals working in social welfare environments which correspond to juridical matters, maintain quite strong views about their abilities to 'change' their clients for the better, even reducing the likelihood of sanctioning if it is felt the individuals involved are cooperating with agencies. The basics of these occupational mentalities are that the work of agencies are ultimately about 'tutelage' - the notion of supervision or control over young people and families, prescribing ways of enacting proper behaviour and conduct, which it is hoped the clients will adopt. As Maynard-Moody and Musheno (2003:106) write; 'if citizen-clients have genuine needs, are of good character, and are motivated to respond to treatment, then they are likely to repay society for street-level workers' investments of time, effort and money'.

Whereas personalised duties of 'doing good' were common with the majority of social service professionals, many of the responses towards more extreme forms of behaviour or conduct were justified on the basis of not only 'antisocial' acts, but a deeper breach of morality shared by professionals. These behaviours or conducts, whilst sometimes allowing legitimate access for legal intervention to take place, were more 
often conveyed through the ways they seemed to contravene professionals' own assessments of what constituted 'proper' or 'desirable' behaviour. This is not to say that morality is somehow structured merely on the individual level, but to suggest that professionals often drew upon a set of narratives in order to illustrate the ways some young people can challenge and ultimately disrupt their occupational moralities, particularly in the case of police officers. In the cases below, the perspectives of two male police officers are highlighted - the first, an example of the softer, be-friending activities of the police and how these may manifest in 'tipping points' of enforcement, the second, a clear example of frustration and resentment voiced by the officer in his failure to supply punishment which sparked antipathy in the young person:

If they cross the boundary and they commit offences of assault, drugs or whatever, I might almost become in their view friendly with them. I have got to keep that distance professionally, but maybe they will see me as a friend and a help to their family. But they also know that if they are doing something like that then I have a job to do as well. Actually I find that works well and find it works quite easy. When I am dealing with it I am not just any old bobby who had picked up that theft report or that drug report, I am that local beat bobby who turns up at their door and says we have got to deal with that. In terms of achievement, getting people to be much more honest and steering people away from causing problems again, it probably works better. They are talking to me and I'm trying to help them, and I am saying I am disappointed that I am sat in the police station with you. I don't really want to be doing this and don't really want to see you being prosecuted but that's what I need to do today. [Interview with Steve, Police Officer]

Whilst I was waiting in the reception of the police station for a meeting, Stuart Dayton [police officer] saw me waiting and we got talking about my research. He said in a blunt, but half joking way 'so you gonna find out the answer then?' I laughed in response, saying 'I wish I could'. He followed 'I don't know what the answers are. For some people prison works, for others it doesn't. I have some lads on my beat who have been so put off by prison they were like 'I'm never going back there again'. D'you know that kid Aaron Mitchell? I replied casually, 'yeah I've heard of him' in a way as to arise no suspicion of personal contact with Aaron [I had interviewed Aaron three times prior to this]. Stuart: 'I never forget what he said to me the day he came out of prison [pause]. Easiest time he'd ever done he said. It was like Butlins ${ }^{7}$ without the water slides'. Stuart seemed physically annoyed even recalling the story seeming to take what Aaron said to him as a personal insult against his actions to put Aaron in prison in the first place. [Informal interview with Stuart, Police Officer]

Although the content was different in terms of the language used, the overall sentiments expressed in the above narratives were common across professionals, including those occupying a more welfarist stance. Occupational moralities should not be strictly aligned with surrogate ideologies for criminalising, but as key features of occupational identities regarding beliefs about how far professionals will engage with supportive methods before 
abandoning these for dictates of formal legal enforcement - actions which were relatively rare in the context of the 'early intervention' cases observed ${ }^{8}$. For the police, the agency with perhaps the least support for 'social work' based philosophies; there was a surprising level of adoption of 'early intervention' methods for diverting young people from criminality. Although there were obvious restrictions regarding the application of these philosophies, with distinctions of moral worth and credibility of clients often structuring the rules of engagement, it should be recognised that these values feature across a range of street-level bureaucracies, and are not strictly confined to the 'macho' image of the police. Work environments frequently consist of making difficult decisions about the use of resources toward certain persons, deciding who should be put to the bottom of the pile with regards services, and ultimately forming ideas of who are the worthy candidates for supporting (Lipsky, 1980, Maynard-Moody and Muscheno, 2003). These distinctions, as this article has suggested, are often structured by class beliefs which accord differential levels of status to persons - often based around the degrees to which they comply and come to adopt the agency determined strategies for 'correcting' their behaviour. This, it is argued, is far deeper than simply cessation or reduction of ASB.

\section{Conclusion}

'Early intervention' strategies which seek to divert young people away from crime and ASB have more to do with class judgements than potentials for offending. This is particularly important given that reasons for intervening are seldom due to problems of crime or ASB in isolation, but rather to aspects of class conduct which are seen as in need of correction. The broader aim of this article has been to analyse how professional judgements, despite benevolent intentions, reproduce inequality and perpetuate the subjugation of dependency on behalf of the clients they serve. It has been illustrated that professionals are engaged more in tasks of 'class correction' through tutelary social control functions, than 'crime control' functions orientated around problems of ASB. The adoption of social class is to understand, as Bev Skeggs articulates, 'how class is made through cultural values premised on morality, embodied in personhood and realized (or not) as a property value in symbolic systems of exchange' (Skeggs, 2005:969). This takes us beyond categorical and somewhat homogeneous ideas of class, to understand how markers of class are utilised in social situations and invoked selectively to stigmatise certain persons as dynamic rather than static processes of labelling.

Pierre Bourdieu (1986) and others since then (e.g. Skeggs, 1997, 2004, Lawler, 2005) have understood social class as a relational struggle for social resources, specifically focusing on the ways power operates to maintain dominant forms of authority. Professionals' judgments made under the auspices of assistance and support, despite containing benevolent intentions, often activate forms of pathology which marked every aspect of their clients lives to scrutiny - the state of their homes, their abilities to parent, their 'lack' of willingness to deal with their own problems, their dirty appearances etc. This, it is argued, has a significant role to play in the continuing classifications of the white working-classes as a distinct group in need of correction, whether via benevolent or more draconian practices. As Bottero (2009:10) argues 'class is always about invidious 
comparison, and when people talk about 'class' their accounts often shift easily from social description, to social evaluation, to social abuse' (original emphasis). As examples during this article have illustrated, practices associated with early intervention can also be invoked through castigations of deficits articulated through 'caring' as well as 'controlling' rhetoric via linkages with ASB. Where ASB becomes the organising principle for supportive as well as controlling interventions, there is an obvious 'net widening' effect established through such practices (Cohen, 1985, McAra and McVie, 2005). This accords with one of the key arguments of this article, that young people and families who show signs of cooperating with agencies, even in instances where involvement in low-level ASB continues, are less likely to receive formal sanctions such as parenting orders and ASBOs. On the one hand, the previous New Labour government has done much to inspire professionals to focus attention on deficits in areas such as parenting through a moral language of lack (Goldson and Jamieson, 2006, Skeggs, 2006). On the other hand, the occupational moralities of professionals in seeking to change behaviour of their clients through supportive as well as 'tough love' intervention plays a crucial role in nurturing tutelary and paternalistic control structures. In short, despite challenging work environments and struggles to supply resources to clients, the controlling dogma and moralities of 'helping' continue to provide a key explanation for continued focus on 'class correction' as an overarching mentality of social control.

\section{Notes}

\footnotetext{
${ }^{1}$ Whilst the term 'early intervention' is used in this article specific to diversionary initiatives and ASB, it should be recognised that the term has a meaning which extends more broadly to social welfare and prevention (see Parton, 2006).

${ }^{2}$ Interviewees consisted of 6 police officers ( 5 female, 1 male), 3 social workers ( 2 female, 1 male), drugs worker (1 female), youth offending officers ( 2 female, 1 male), housing officers/community wardens ( 2 male, 1 female), local authority officers (2 males).

${ }^{3}$ Overall referrals consisted of; police 77\% (Hobart), 59\% (Shore Acres), Housing Landlords - 17\% (Hobart) 35\% (Shore Acres), Social Services - 1\% (Hobart only), Local Authority - 2\% (Hobart and Shore Acres), Youth Offending Team 2\% (Hobart), 4\% (Shore Acres) $(n=204)$

${ }^{4}$ PCSOs are uniformed police officers established in England and Wales in 2002 to provide a reassurance presence and deal with low-level incivilities. Unlike formal police officers, they do not have powers of arrest, but have powers to issue fines and fixed penalty notices.

${ }^{5}$ Anti-Social Behaviour Injunction (ASBI) - an injunction granted by the courts during instances where a social housing tenant carries out disproportionate levels of ASB which causes considerable impact to neighbours. If breached, powers of arrest can be attached to the orders, and tenants may lose their property as a result.

${ }^{6}$ For example, social housing, living on welfare, often single parent households, several young children.

${ }^{7}$ For unfamiliar readers, Butlins is a holiday camp resort based in coastal regions around the UK which consists of organised fun-based activities for primarily children and families.

${ }^{8}$ During the course of the case conferences, $60 \%$ of cases were referred to support services, $40 \%$ received Acceptable Behaviour Contracts (often in conjunction with support), 20\% receiving parenting contracts, with 4\% receiving Anti-Social Behaviour Orders or criminal charges rendering a custodial penalty.
}

\section{References}


Association of Chief Police Officers (2008) ACPO Youth Strategy, London, ACPO

Baker, J (2009) 'Young Mothers in Late Modernity: Sacrifice, Respectability and the Transformative Neo-Liberal Subject', Journal of Youth Studies, 12 (3), 275-288

Bourdieu, P (1986) Distinction: A Social Critique of the Judgement of Taste, London, Routledge

Bourdieu, P (1991) Language and Symbolic Power, trans Raymond, G, Adamson, M, Cambridge, Polity Press

Blomberg, T (1977) 'Diversion and Accelerated Social Controls', Journal of Criminal Law and Criminology, 68 (2), 274-82

Bottero, W (2009) 'Class in the $21^{\text {st }}$ Century', in Sveinsson, K, P (ed), Who Cares about the White Working Class? Runnymede Trust, London

Burney, E (2005) Making People Behave: Anti-Social Behaviour Policy and Politics, Cullompton, Willan Publishing

Clarke, K (2006) 'Childhood, Parenting and Early Intervention: A Critical Evaluation of the Sure Start National Programme', Critical Social Policy, 26 (4), 699-721

Cohen, S (1979) 'The Punitive City: Notes on the Dispersal of Social Control', Contemporary Crises, 3(4), 341-363

Cohen, S (1985) Visions of Social Control, Cambridge, Polity Press

Dodson, L (2007) 'Wage-Poor Mothers and the Moral Economy', Social Politics, Vol 14, $258-280$

Donzelot, J (1978) The Policing of Families, New York, Pantheon

Emerson, R (1969) Judging Delinquents, Chicago, Aldine Press

Farrington, D (2007) 'Childhood Risk Factors and Risk-Focussed Prevention', in Maguire, M, Morgan, R, Reiner, R (eds) The Oxford Handbook of Criminology, (Third ed), Oxford, Oxford University Press

Farrington, D, Welsh, B (2006) Saving Children from a Life of Crime: Early Risk Factors and Effective Interventions, New York, Oxford University Press

Finch, L (1993) The Classing Gaze: Sexuality, Class and Surveillance, St Leonards: NSW, Allen and Unwin 
Foster, J (2002) 'People Pieces': the neglected but essential elements of community crime prevention', in Hughes, G, Edwards, A (eds), Crime Control and Community: The new politics of public safety, Cullompton, Willan

Garrett, M (2006) 'Making 'Anti-Social Behaviour': A Fragment on the Evolution of 'ASBO Politics' in Britain', British Journal of Social Work, 37, 839-856

Gillies, V (2005) 'Meeting parents 'needs'? Discourses of support and inclusion in family policy’, Critical Social Policy, 25 (1), 70-90

Gillies, V (2008) 'Childrearing, Class, and the New Politics of Parenting', Sociology Compass, 2 (3), 1079- 1095

Goldson, B (2000) (ed) The New Youth Justice, Lyme Regis, Russell House Publishing

Goldson, B, Jamieson, J (2002) 'Youth Crime, the 'Parenting Deficit' and State Intervention: A Contextual Critique', Youth Justice, 2 (2), 82-99

Hayward, R, Sharp, C (2005) 'Young People, Crime, and Anti-Social Behaviour: Findings from the 2003 Crime and Justice Survey', London, Home Office

Harris, A (2008) "The Social Construction of "Sophisticated" Adolescents: How Judges Integrate Criminal Justice Decision-Making Models', Journal of Contemporary Ethnography, 37 (4), 469-506

Hartigan, J, Jnr (1999) Racial Situations: Class Predicaments of Whiteness in Detroit, Princeton, Princeton University Press

Hey, V, Bradford, S (2006) 'Re-engineering Motherhood? Sure Start in the Community', Contemporary Issues in Early Childhood, 7 (1), 53-67

Home Office (2003) Respect and Responsibility: Taking a Stand Against Anti-Social Behaviour, London, HMSO

Home Office (2004) Building Communities, Beating Crime, London, HMSO

Home Office (2008) Youth Crime Action Plan, London, HMSO

Home Office (2010) Safe and Confident Neighbourhood Strategy, London, HMSO

Jamieson, J (2005) 'New Labour, Youth Justice, and the Question of 'Respect', Youth Justice, 5 (3), 180-193

Johnson, P (2008) 'Rude Boys': The Homosexual Eroticization of Class', Sociology, 42 (1), $65-82$ 
Labour Party (2009) Connecting Communities, London, Department for Communities and Local Government

Lawler, S (2005) 'Disgusted Subjects: The Making of Middle-Class Identities', The Sociological Review, 53 (3), 429-46

Lipsky, M (1980) Street-Level Bureaucracy, New York, Russell Sage Foundation

Loeber, R (1982) 'The Stability of Antisocial and Delinquent Child Behavior: A Review', Child Development, 53 (6), 1431-1446

Maynard-Moody, S, Musheno, M (2003) Cops, Teachers and Counselors: Stories from the Front Lines of Public Service, Ann Arbor, University of Michigan Press

McAra, L McVie, S (2005) Youth Justice? The Impact of System Contact on Patterns of Desistence from Offending, European Journal of Criminology, Vol. 4, No. 3, 315-345

Millie, A, Jacobson, J, Hough, M (2005) 'Anti-Social Behaviour Strategies: Finding a Balance', York, Joseph Rowntree Foundation

Nixon, J, Hunter, C (2009) 'Disciplining Women and the Governance of Conduct', in Millie, A, E (ed), Securing Respect: Behavioural Expectations and Anti-Social Behaviour in the $U K$, Bristol, Policy Press

Parton, N (2006) Safeguarding Children: Early Intervention and Surveillance in Late Modern Society, Basingstoke, Palgrave/Macmillan

Platt, A (1969) The Child Savers: The Invention of Delinquency, Chicago, University of Chicago Press

Respect Task Force (2006) Respect Action Plan, London, HMSO

Roberts, I (1999) 'A Historical Construction of the Working Class', in Beynon, H, Glavanis, P (eds), Patterns of Social Inequality, London, Longman, pp147-160

Rutherford, A (2000) 'An Elephant on the Doorstep: Criminal Policy without Crime in New Labour's Britain', in Rutherford, A, Green, P (eds), Criminal Policy in Transition, London, Hart Publishing, pp33-62

Rutter, M, Giller, H, Hagell, A, (1998) Antisocial Behaviour and Young People, Cambridge, Cambridge University Press

Rothman, D (1978) 'State as Parent', in Gaylin, W, Rothman, D, Marcus, S (1976) Doing Good: The Limits of Benevolence, Westminster: Maryland, Random House, pp 69-96 
Savage, M (2000 Class Analysis and Social Transformation, Bucks, Open University Press

Scott, S, Knapp, M, Henderson, J, Maughan, B (2001) 'Financial Costs of Social Exclusion: Follow-Up Study of Anti-Social Children into Adulthood', British Medical Journal, Vol 323, 191-194

Scott, S (2002) Review of 'On Track' Anti-Social Behaviour Prevention Program in Southwark, London, Home Office

Skeggs, B (1997) Formations of Class and Gender: On Becoming Respectable, London, Sage

Skeggs, B (2004) Class, Self and Culture, London, Sage

Skeggs, B (2005) 'The Making of Class and Gender through Visualizing Moral Subject Formation', Sociology, 39 (5), 965-982

Skeggs, B (2006) 'Respectability: Becoming a Proper Person', Inaugural Lecture to Goldsmiths College, London, 24/10/06

Skinns, L (2008) 'A Prominent Partner? The Role of the State in Police Partnerships', Policing and Society, 18 (3), 311-321

Souhami, A (2007) Transforming Youth Justice: Occupational Identity and Cultural Change, Cullompton, Willan Publishing

Squires, P (2006) 'New Labour and the Politics of Anti-Social Behaviour', Critical Social Policy, 26 (1), 144-168

Squires, P, Stephen, D, E (2005) Rougher Justice: Anti-Social Behaviour and Young People, Cullompton, Willan Publishing

Wimmer, A (2008) 'The Making and Unmaking of Ethnic Boundaries: A Multilevel Process Theory', American Journal of Sociology , 113 (3), 970-1022

Youth Taskforce Action Plan (2008) London, Department for Children, Schools and Families 


\section{Acknowledgements}

The author would like to thank Nigel Fielding and Paul Johnson, as well as the helpful comments from the three anonymous reviewers. Thanks also go to Helen Moore who directed me to some useful sources on ethnicity and social class. I also acknowledge funding from the Economic and Social Research Council (PTA - 031-2006-00462).

\section{Biography}

Daniel McCarthy is Lecturer in Criminology in the Department of Sociology, University of Surrey. His publications include 'Self Governance or Professionalized Paternalism: The Police, Contractual Injunctions, and the Differential Management of Deviant Populations' (The British Journal of Criminology, 2010). His expertise consists of policing, youth justice, social control and social theory. Address: Department of Sociology, University of Surrey, Guildford, UK, GU2 7XH, e-mail:

d.mccarthy@surrey.ac.uk 